Article

\title{
An Efficiency Method for Assessment of Shear Stress in Prismatic Beams with Arbitrary Cross-Sections
}

\author{
Dang-Bao Tran ${ }^{1,2, * \mathbb{C}}$, Jaroslav Navrátil ${ }^{1, *}$ and Martin Čermák ${ }^{3, *}$ \\ 1 Department of Structures, Faculty of Civil Engineering, VSB-Technical University of Ostrava, \\ Ludvíka Podéště 1875/17, 70800 Ostrava, Czech Republic \\ 2 Department of Civil Engineering, Faculty of Architecture, Thu Dau Mot University, Tran Van on 06, \\ Thu Dau Mot City 75000, Vietnam \\ 3 Department of Mathematics, Faculty of Civil Engineering, VSB-Technical University of Ostrava, \\ Ludvíka Podéště 1875/17, 70800 Ostrava, Czech Republic \\ * Correspondence: dang.bao.tran.st@vsb.cz (D.-B.T.); jaroslav.navratil@vsb.cz (J.N.); martin.cermak@vsb.cz (M.Č.)
}

Citation: Tran, D.-B.; Navrátil, J.; Čermák, M. An Efficiency Method for Assessment of Shear Stress in Prismatic Beams with Arbitrary Cross-Sections. Sustainability 2021, 13, 687. https://doi.org/10.3390/ su13020687

Received: 30 November 2020 Accepted: 8 January 2021 Published: 12 January 2021

Publisher's Note: MDPI stays neutral with regard to jurisdictional clai$\mathrm{ms}$ in published maps and institutional affiliations.

Copyright: () 2021 by the authors. Licensee MDPI, Basel, Switzerland. This article is an open access article distributed under the terms and conditions of the Creative Commons Attribution (CC BY) license (https:// creativecommons.org/licenses/by/ $4.0 /)$.

\begin{abstract}
The dimensions of a bearing structure tend to be designed as slender as possible to ensure aesthetics and to save material, which makes the structure more susceptible to damage caused by shear forces. When the structure is subjected to an earthquake, the shear failure is even the primary mode of failure. Research on shear stress has always been of great interest to scientists. This paper presents an efficient method for the assessment of the shear stress for prismatic beams with arbitrary cross-section. The numerical method implemented in a MATLAB environment is validated by analyzing five examples. The study shows the efficiency and reliability of the numerical method, which allows for more precise analysis and design of cross-sections. Therefore, significant savings of material can be reached, which will have a positive impact on our environment and which can help sustainable growth.
\end{abstract}

Keywords: Gruttmann shear stress; Saint Venant torsion and torsionless bending; nine-noded quadrilateral element

\section{Introduction}

Engineers tend to design the dimensions of load-bearing structural elements as slender as possible to ensure aesthetic appearance and to reduce material consumption requirements. Considering the fact that nowadays most load-bearing systems of buildings and bridges are created by reinforced prestressed concrete structures, the decrease of the need for concrete would certainly reduce carbon dioxide (CO2) emissions and global warming and, therefore, would contribute to keep economic development sustainable. On the other hand, the effort to design slender and aesthetic structures makes them more susceptible to damage by shear stress. Figure 1a shows the shear failure cases of the American Air force warehouses in 1955 and 1956 [1]. Figure 1b depicts the shear failure of a squat bridge pier during a Taiwan 1999 earthquake [2].

The accurate determination of shear stress is one of the factors to ensure the sustainability of a structure, which is a problem that attracts researchers. Many scientists [3-23] have studied numerical methods dealing with shear stress due to bending and torsion.

Gruttmann, F. et al. $[3,4]$ used the finite element method to evaluate shear stress by using the warping function, which is more convenient than using the Prandtl's stress function $[24,25]$ when considering multiply connected domain. Gruttmann, F. [4] introduced a method for computing the shear correction factors for Timoshenko beams with arbitrary cross-sections. Gruttmann's numerical method has been implemented into an enhanced version of the program FEAP $[5,6,26]$ which used 4-noded isoparametric elements. Fialko, S. Yu et al. [7] developed a numerical method using constant triangular elements to solve the Saint Venant problem of torsion, and torsionless bending of prismatic bars is realized in the SCAD software [8]. 


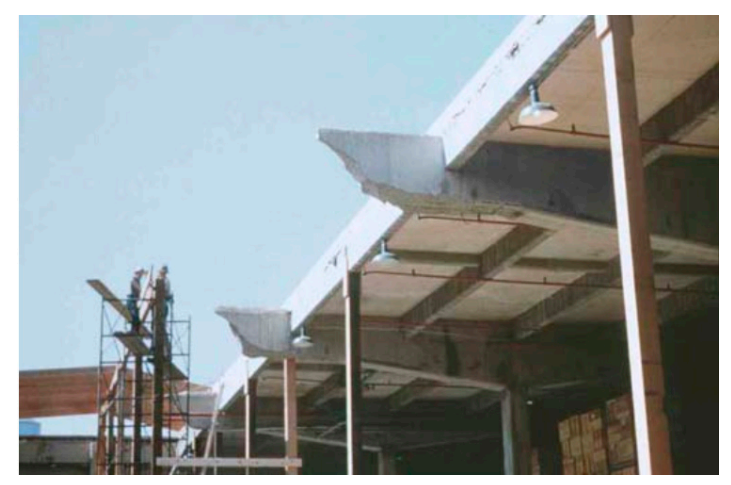

(a)

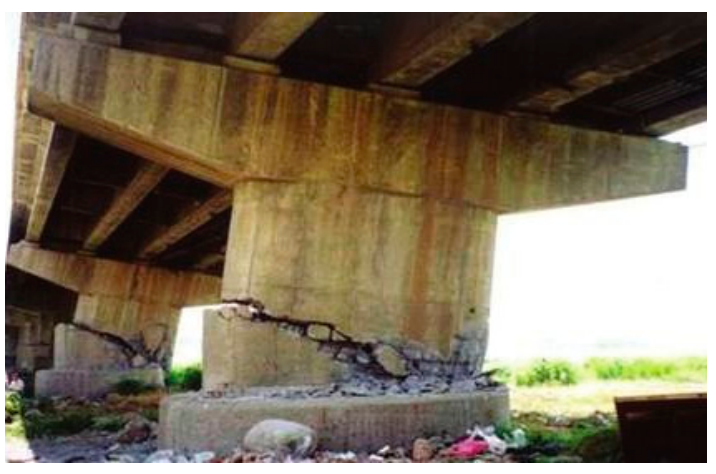

(b)

Figure 1. (a) Shear failure of Air Force Warehouse beams [1]. (b) Shear failure of pier wall of the Wu-Shi Bridge in the Chi-Chi earthquake [2].

Garcia, J.M.B. et al. [9,10] developed a method of analysis to deal with arbitrary cross-section and general non-linear material (i.e., concrete). Poliotti, M. [11] improved Garcia's method's computation speed using b-spline interpolation to reduce unknowns when solving problems. Yoon, K. et al. [14] proposed a new efficient warping displacement model. The model can be used for discontinuously varying cross-section beams. However, the method does not take into account the multiply connected domains. A comparison of methods for the strength assessment of prestressed reinforced concrete cross-sections with respect to the interaction of tensile and shear forces and bending and torsional moments was performed by Navrátil, J. et al. [13]. Genoese, A. [14] proposed a method for determining only the shear stress for nonuniform torsion. Jog, C.S. [15] demonstrated a method for determining the shear stress due to bending and torsion for inhomogeneous materials. However, the coupling of bending and torsion was not considered. Urbański, A. [16] studied a finite element method considering the interaction of internal force components with arbitrary cross-section. However, the multiply connected domain was not considered. Beheshti, A. [17] contributed to a method of determining the shear stress due to torsion, including strain-gradient elasticity.

Sapountzakis, E.J. et al. $[18,19]$ proposed the nonuniform torsion solution and the general transverse shear loading problem of beams of the arbitrary cross-section with the boundary element method. Barone, G. [20] used the complex variable boundary element method to evaluate shear stress caused by torsion and flexure in beams. Paradiso, M. [21] introduced a numerical method based on the boundary element method to determine shear stress in the Saint Venant theory of beam. A boundary approach labeled line elementless method was recently shown to solve the Saint Venant's flexure-torsion problem for isotropic material and arbitrary cross-sections by Di Paola, M. et al. [22].

In summary, the existing literature has constructed a large number of numerical methods for the shear stress problem. All of the works demonstrate the feasibility and effectiveness only in academia. Currently, only Gruttmann's method [3,4] has been developed into the FEAP program [6] of the University of California, Berkeley, and Allplan Bridge [23]. Fialko's method [7] is similar to that of Grutmmann, which has been developed as a module in the SCAD commercial software [8]. It means the methods of Gruttmann and Fialko are practical. However, the authors found that using a 4-noded isoparametric element in FEAP and constant strain triangle element in SCAD takes a lot of time for meshing to achieve optimal results. So, the authors decided to develop a new numerical method (NMB) based on the work of Gruttmann using the nine-noded isoparametric element. The validation examples were performed to show the reliability and efficiency of the sustainability design of NMB. 


\section{Solution Procedure by Numerical Method}

Consider a prismatic bar with an arbitrary constant cross-section. The longitudinal axis is the $x$-axis, and the cross-sections lie in the $y-z$ plane, see Figure 2 . The parallel system $\bar{y}=y-y_{S}$ and $\bar{z}=z-z_{S}$ intersects at the centroid. The multiply connected domain $\Omega$ is bounded by $\Gamma_{1}, \Gamma_{2}, \ldots \Gamma_{n-1}, \Gamma_{n}$. On $\Gamma_{1}, \Gamma_{2}, \ldots \Gamma_{n-1}, \Gamma_{n}$ the right-handed orthogonal basis system is defined with tangent vector $\mathbf{t}$ and outward normal vector $\mathbf{n}=\left[n_{y}, n_{z}\right]^{T}$. With $\mathbf{t}$, the orientation of the associated coordinate $s$ is uniquely defined.

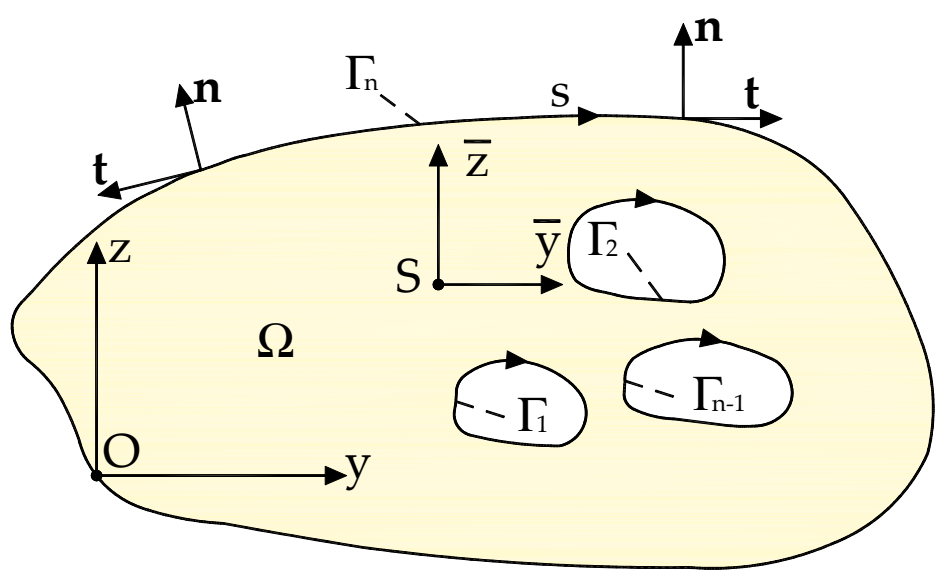

Figure 2. Cross-section of a prismatic bar.

\subsection{Saint Venant Torsion Problem}

The displacement field $\mathbf{u}=\left[u_{x}, u_{y}, u_{z}\right]^{T}$ is given by

$$
u_{x}=\alpha \omega^{T}, u_{y}=-\beta_{x} z, u_{z}=-\beta_{x} y,
$$

where $\beta_{x}$ is torsion angle and $\alpha=\frac{d \beta_{x}}{d x}, \omega^{T}(y, z)$ denotes warping function for torsion. Here, the following constraint is required:

$$
\int_{\Omega} \omega^{T} d A=0
$$

The shear stresses are defined by

$$
\tau_{x y}=G \alpha\left(\frac{\partial \omega^{T}}{\partial y}-z\right), \tau_{x z}=G \alpha\left(\frac{\partial \omega^{T}}{\partial z}+y\right) .
$$

The polar second moment of area can read as

$$
I_{T}=\int_{\Omega}\left[\left(\frac{\partial \omega^{T}}{\partial z}+y\right) y-\left(\frac{\partial \omega^{T}}{\partial y}-z\right) z\right] d A .
$$

The strong form of the boundary value problem is described by

$$
\begin{aligned}
& \frac{\partial^{2} \omega^{T}}{\partial^{2} y}+\frac{\partial^{2} \omega^{T}}{\partial^{2} z}=0 \text { in } \Omega, \\
& n_{y} \frac{\partial \omega^{T}}{\partial y}+n_{z} \frac{\partial \omega^{T}}{\partial z}=n_{y} z-n_{z} y \text { on } \partial \Omega,
\end{aligned}
$$

where

$$
n_{y}=\frac{d z}{d s}, n_{z}=-\frac{d y}{d s} .
$$


Using the Galerkin method, with test function $\eta \in V$ with $V=\left\{\eta \in H^{1}(\Omega), \eta=0\right.$ on $\left.\partial \Omega_{\omega^{T}}\right\}$, Gruttmann, F. [3] transformed the strong form (5) to the weak form as below:

$$
G\left(\omega^{T}, \eta\right)=\int_{\Omega}\left(\frac{\partial \omega^{T}}{\partial y} \frac{\partial \eta}{\partial y}+\frac{\partial \omega^{T}}{\partial z} \frac{\partial \eta}{\partial z}\right) d A-\oint_{\partial \Omega}\left(n_{y} z-n_{z} y\right) \eta d s=0 .
$$

\subsection{Saint Venant Torsionless Bending Problem}

From reference [4], the relation between shear forces $Q_{y}$ and $Q_{z}$ and the corresponding, bending-related normal stress component, $\sigma_{x}$, is given in the format

$$
\frac{\partial \sigma_{x}}{\partial x}=f_{0}(y, z)=a_{1} \bar{y}+a_{2} \bar{z},
$$

where proportionality factors $a_{1}$ and $a_{2}$ are defined as

$$
\left[\begin{array}{l}
a_{1} \\
a_{2}
\end{array}\right]=\frac{1}{A_{\overline{y y}} A_{\overline{z z}}-A_{\overline{y z}}^{2}}\left[\begin{array}{cc}
A_{\overline{z z}} & -A_{\overline{y z}} \\
-A_{\overline{y z}} & A_{\overline{y y}}
\end{array}\right]\left[\begin{array}{l}
Q_{y} \\
Q_{z}
\end{array}\right],
$$

where $Q_{y}$ and $Q_{z}$ are related to shear stress component via

$$
Q_{y}=\int_{(\Omega)} \tau_{x y} d A, Q_{z}=\int_{(\Omega)} \tau_{x z} d A,
$$

where $A_{\overline{y y}}, A_{\overline{z z}}, A_{\overline{y z}}$ are the second-order area moments, defined by

$$
A_{\overline{y y}}=\int_{(\Omega)} \bar{y}^{2} d A, A_{\overline{z z}}=\int_{(\Omega)} \bar{z}^{2} d A, A_{\bar{y} z}=\int_{(\Omega)} \overline{y z} d A .
$$

The shear stresses are defined by

$$
\tau_{x y}=\frac{\partial \omega^{B}}{\partial y}-f_{1}(z), \tau_{x z}=\frac{\partial \omega^{B}}{\partial z}-f_{2}(y),
$$

where $\omega^{B}$ is warping function due to torsionless bending. Furthermore, the functions

$$
f_{1}(z)=-\frac{v}{2(1+v)} a_{1}\left(z-z_{0}\right)^{2}, f_{2}(y)=-\frac{v}{2(1+v)} a_{2}\left(y-y_{0}\right)^{2},
$$

where $v$ is Poisson's ratio. The parameters $y_{0}, z_{0}$ are derived from the following formulations:

$$
y_{0}=\frac{B_{y y}}{2 B_{y}}, z_{o}=\frac{B_{z z}}{2 B_{z}}
$$

where

$$
\begin{aligned}
B_{y} & =\int_{(\Omega)}\left(\frac{\partial \omega^{T}}{\partial z}+y\right) \mathrm{y} d A, B_{y y}=\int_{(\Omega)}\left(\frac{\partial \omega^{T}}{\partial z}+y\right) \mathrm{y}^{2} d A, \\
B_{z} & =\int_{(\Omega)}\left(\frac{\partial \omega^{T}}{\partial y}-z\right) \mathrm{z} d A, B_{z z}=\int_{(\Omega)}\left(\frac{\partial \omega^{T}}{\partial y}-z\right) \mathrm{z}^{2} d A,
\end{aligned}
$$

where $\omega^{T}$ is warping function due to torsion.

The strong form of the boundary value problem is described by

$$
\begin{aligned}
& \frac{\partial^{2} \omega^{B}}{\partial^{2} y}+\frac{\partial^{2} \omega^{B}}{\partial^{2} z}+f_{o}(y, z)=0 \text { in } \Omega, \\
& \tau_{x y} n_{y}+\tau_{x z} n_{z}=0 \text { on } \partial \Omega,
\end{aligned}
$$


where

$$
n_{y}=\frac{d z}{d s}, n_{z}=-\frac{d y}{d s} .
$$

Using the Galerkin method, with test function $\eta \in V$ with $V=\left\{\eta \in H^{1}(\Omega), \eta=0\right.$ on $\left.\partial \Omega_{\omega^{B}}\right\}$, Gruttmann, F. [4] transformed the strong form (16) to the weak form as below:

$$
G\left(\omega^{B}, \eta\right)=\int_{\Omega}\left(\frac{\partial \omega^{B}}{\partial y} \frac{\partial \eta}{\partial y}+\frac{\partial \omega^{B}}{\partial z} \frac{\partial \eta}{\partial z}\right) d A-\int_{\Omega}\left(f_{0} \eta+f_{1} \frac{\partial \eta}{\partial y}+f_{2} \frac{\partial \eta}{\partial z}\right) d A=0 .
$$

\subsection{Finite Element Discretization}

Consider the cross-section divided by nine-noded isoparametric quadrilateral elements. $\mathbf{x}=[y, z]^{T}$ and the unknown function $\omega^{T}, \omega^{B}$, and the test function $\eta$ are interpolated within a typical element using the same shape functions:

$$
\begin{gathered}
\mathbf{x}^{h}=\sum_{I=1}^{9} N_{I}(\xi, \eta) \mathbf{x}_{I},\left(\omega^{T}\right)^{h}=\sum_{I=1}^{9} N_{I}(\xi, \eta) \omega_{I}^{T}, \\
\left(\omega^{B}\right)^{h}=\sum_{I=1}^{9} N_{I}(\xi, \eta) \omega_{I}^{B},(\eta)^{h}=\sum_{I=1}^{9} N_{I}(\xi, \eta) \eta_{I}
\end{gathered}
$$

where $h$ denotes the approximate solution of the finite element method. $N_{I}(\xi, \eta)$ denotes the shape function of the element. Figure 3 shows the nine-noded isoparametric quadrilateral element used in NMB. From reference [27], the shape functions $N_{I}(\xi, \eta)$ of this element can be described as follows:

$$
\begin{gathered}
N_{1}(\xi, \eta)=\frac{\xi(\xi-1) \eta(\eta-1)}{4}, N_{2}(\xi, \eta)=\frac{(\xi+1) \xi \eta(\eta-1)}{4}, N_{3}(\xi, \eta)=\frac{(\xi+1) \xi(\eta+1) \eta}{4}, \\
N_{4}(\xi, \eta)=\frac{\xi(\xi-1)(\eta+1) \eta}{4}, N_{5}(\xi, \eta)=\frac{(\xi+1)(\xi-1) \eta(\eta-1)}{-2}, \\
N_{6}(\xi, \eta)=\frac{(\xi+1) \xi(\eta+1)(\eta-1)}{-2}, N_{7}(\xi, \eta)=\frac{(\xi+1)(\xi-1)(\eta+1) \eta}{-2}, \\
N_{8}(\xi, \eta)=\frac{\xi(\xi-1)(\eta+1)(\eta-1)}{-2}, N_{9}(\xi, \eta)=\frac{(\xi+1)(\xi-1)(\eta+1)(\eta-1)}{1} .
\end{gathered}
$$

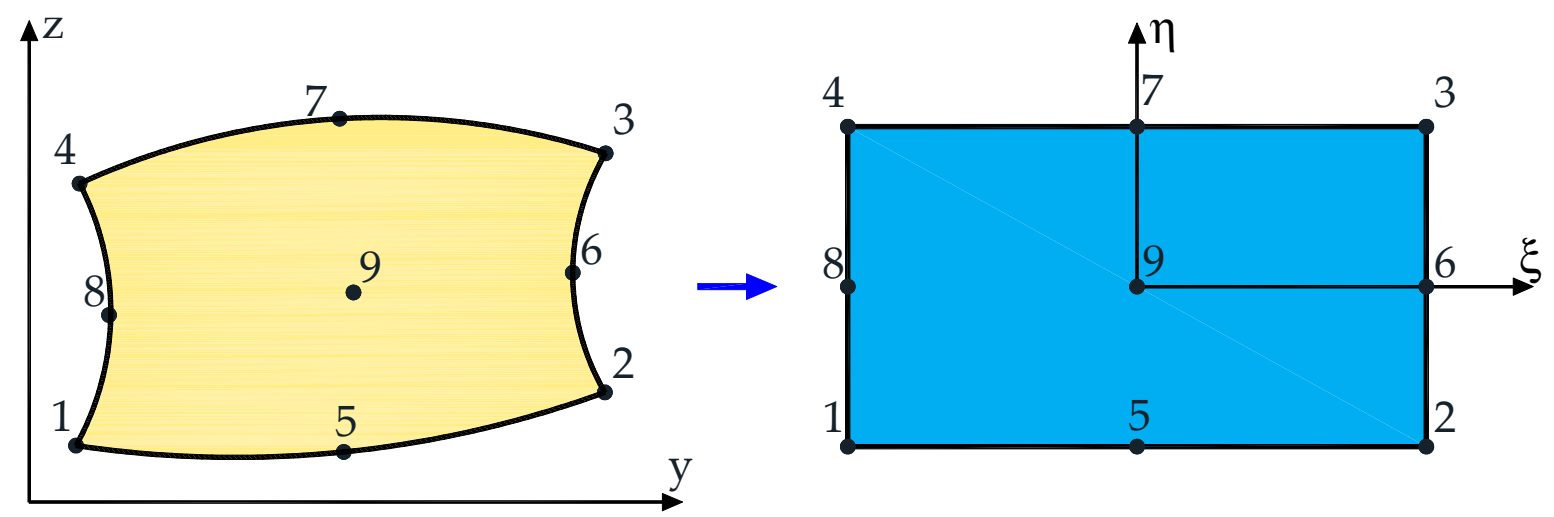

Figure 3. Nine-noded isoparametric quadrilateral element.

Inserting the derivatives of $\left(\omega^{T}\right)^{h}, \eta^{h}$ and $\left(\omega^{B}\right)^{h}$, into the weak forms of (7) and (18), respectively, yields the finite element equations

$$
\begin{aligned}
& \bigcup_{e=1}^{\text {numel }} \sum_{I=1}^{9} \sum_{K=1}^{9} \delta \omega_{I}^{T}\left(K_{I K}^{e} \omega_{K}^{T}-F_{I}^{e(T)}\right)=0, \\
& \bigcup_{e=1}^{\text {numel }} \sum_{I=1}^{9} \sum_{K=1}^{9} \delta \omega_{I}^{B}\left(K_{I K}^{e} \omega_{K}^{B}-F_{I}^{e(B)}\right)=0
\end{aligned}
$$


The operator $\cup$ describes the assembly and numel the total number of finite elements to solve the problem. The stiffness part, $K_{I K}^{e}$, to the nodes $I$ and $K$ as well as the right hand $F_{I}^{e(T)}$ and $F_{I}^{e(B)}$ yields

$$
\begin{aligned}
& K_{I K}^{e}= \int_{\Omega_{e}}\left(\frac{\partial N_{I}}{\partial y} \frac{\partial N_{K}}{\partial y}+\frac{\partial N_{I}}{\partial z} \frac{\partial N_{K}}{\partial z}\right) d A_{e} \\
&= \int_{-1}^{1} \int_{-1}^{1}\left(\frac{\partial N_{I}}{\partial y} \frac{\partial N_{K}}{\partial y}+\frac{\partial N_{I}}{\partial z} \frac{\partial N_{K}}{\partial z}\right)|\mathbf{J}| d \xi d \eta \\
&= \sum_{p=1}^{P} \sum_{q=1}^{\ell} w_{p} w_{q}\left(\frac{\partial N_{I}}{\partial y}\left(\xi_{p}, \eta_{q}\right) \frac{\partial N_{K}}{\partial y}\left(\xi p, \eta_{q}\right)+\frac{\partial N_{I}}{\partial z}\left(\xi_{p}, \eta_{q}\right) \frac{\partial N_{K}}{\partial z}\left(\xi_{p}, \eta_{q}\right)\right)\left|\mathbf{J}\left(\xi_{p}, \eta_{q}\right)\right|, \\
& F_{I}^{e(T)}=\int_{\Omega_{e}}\left(\frac{\partial N_{I}}{\partial y} z-\frac{\partial N_{I}}{\partial z} y\right) d A_{e} \\
&=\int_{-1}^{1} \int_{-1}^{1}\left(\frac{\partial N_{I}}{\partial y} z+\frac{\partial N_{I}}{\partial z} y\right)|\mathbf{J}| d \xi d \eta \\
&=\sum_{p=1}^{P} \sum_{q=1}^{Q} w_{p} w_{q}\left(\frac{\partial N_{I}}{\partial y}\left(\xi_{p}, \eta_{q}\right) z-\frac{\partial N_{I}}{\partial z}\left(\xi_{p}, \eta_{q}\right) y\right)\left|\mathbf{J}\left(\xi_{p}, \eta_{q}\right)\right|, \\
& F_{I}^{e(B)}=\int_{\Omega_{e}}\left(f_{0} N_{I}+f_{1} \frac{\partial N_{I}}{\partial y}+f_{2} \frac{\partial N_{I}}{\partial z}\right) d A_{e} \\
&=\int_{-1}^{1} \int_{-1}^{1}\left(f_{0} N_{I}+f_{1} \frac{\partial N_{I}}{\partial y}+f_{2} \frac{\partial N_{I}}{\partial z}\right)|\mathbf{J}| d \xi d \eta \\
&=\sum_{p=1}^{P} \sum_{q=1}^{Q} w_{p} w_{q}\left(f_{0} N_{I}\left(\xi_{p}, \eta_{q}\right)+f_{1} \frac{\partial N_{I}\left(\xi_{p}, \eta_{q}\right)}{\partial y}+f_{2} \frac{\partial N_{I}\left(\xi_{p}, \eta_{q}\right)}{\partial z}\right)\left|\mathbf{J}\left(\xi_{p}, \eta_{q}\right)\right|,
\end{aligned}
$$

where $\mathbf{J}$ denoted as Jacobian matrix is defined as

$$
\mathbf{J}=\left[\begin{array}{ll}
\frac{\partial y}{\partial \xi} & \frac{\partial z}{\partial \eta} \\
\frac{\partial y}{\partial \xi} & \frac{\partial z}{\partial \eta}
\end{array}\right],
$$

where $w_{p}$ and $w_{q}$ are the weights and $\xi_{p}$ and $\eta_{q}$ are the integration points of the Gaussian integration technique.

We use $3 \times 3$ Gauss quadrature derived from the 1D case where the quadrature points are located at $-\sqrt{3 / 5}, 0$, and $\sqrt{3 / 5}$, and the corresponding weights are equal to $5 / 9,8 / 9$, and 5/9, respectively (see reference [26]).

The value $\omega_{I}^{T}$ and $\omega_{I}^{B}$ of one arbitrary nodal point $I$ has to be value 0 .

From reference [24], shear correction factor $\kappa$ is the ratio of the average strain on a section to the shear strain at the centroid. Gruttmann, F. [4] used it as the criterion to evaluate the convergence solutions to the Saint Venant torsionless bending problem. The shear correction factor $\kappa_{y}, \kappa_{z}$ is computed as

$$
\kappa_{y}=1 / \alpha_{y}, \kappa_{z}=1 / \alpha_{z}
$$

where

$$
\begin{aligned}
& \alpha_{y}=\frac{A}{Q_{y}}\left[\frac{A_{\omega} B_{\bar{y}} A_{\overline{z z}}-A_{\omega B} A_{\bar{y} \bar{z}}}{A_{\overline{y y}} A_{\overline{z z}}-A_{\overline{y z}}^{2}}+\frac{v}{2(1+v)} \frac{C_{z z} A_{\overline{z z}}-C_{y y} A_{\overline{y z}}}{A_{\overline{y y}} A_{\overline{z z}}-A_{\overline{y z}}^{2}}\right], \\
& \alpha_{z}=\frac{A}{Q_{z}}\left[\frac{A_{\omega B_{\bar{z}}} A_{\overline{y y}}-A_{\omega B_{\bar{y}}} A_{\overline{y z}}}{A_{\overline{y y}} A_{\overline{z z}}-A_{\overline{y z}}^{2}}+\frac{v}{2(1+v)} \frac{C_{y z} A_{\overline{y y}}-C_{z z} A_{\overline{y z}}}{A_{\overline{y y}} A_{\overline{z z}}-A_{\overline{y z}}^{2}}\right],
\end{aligned}
$$

where

$$
\begin{gathered}
C_{y y}=\int_{(\Omega)} \tau_{x z}\left(y-y_{0}\right)^{2} d A, C_{z z}=\int_{(\Omega)} \tau_{x y}\left(z-z_{0}\right)^{2} d A, \\
A_{\omega^{B} \bar{z}}=\int_{(\Omega)} \omega^{B} \bar{z} d A, A_{\omega^{B} \bar{y}}=\int_{(\Omega)} \omega^{B} \bar{y} d A .
\end{gathered}
$$




\section{Validation Examples}

The objective of this section is to show the assessment of NMB and its performance. For this purpose, five special problems derived from references $[3,4,7,24]$ were studied and their results compared with those predicted by NMB implemented in MATLAB R2015a. The finite element discretization was realized by employing the SAP2000 software version 14.2 [28] and MATLAB of an in-house code. We used a part of the open-source library presented in reference [29].

\subsection{Rectangular Cross-Section}

To test the problem of torsion, we considered a bar of square cross-section subjected to the torsion moment $M_{T}=1$ [MN.m] with the length of the edge 1 [m]. The comparison of the values of maximum shear stress and polar second moment of area obtained by analytical solution [24] was performed. The visualization of the distribution of shear stress was also displayed.

We checked the problem of the torsionless bending of a rectangular cross-section on the basis of the comparison with the results of [3,4]. Shear correction factors $\kappa_{z}=1 / \alpha_{z}$ were the evaluated criteria. We investigated the rectangular cross-section due to $Q_{z}=1$ $[\mathrm{kN}]$ with the dimensions $(h=2[\mathrm{~m}], b=1[\mathrm{~m}]),(h=1[\mathrm{~m}], b=1[\mathrm{~m}]),(h=0.5[\mathrm{~m}], b=1$ $[\mathrm{m}]),(h=0.25[\mathrm{~m}], b=1[\mathrm{~m}])$ corresponding with the ratio $(h / b=2,1,0.5,0.25)$ and with different Poisson's ratio $v=0,0.25,0.5$. The distribution of shear stress with two Poisson's ratios, $v=0,0.25$, was also shown.

The maximum shear stress corresponding to the maximum slope of the membrane is at the middle points of the long sides of the rectangle [24]. It means the distribution of shear stress of the square section decreases from the middle point of the edge to the center. Figure 4 shows a good agreement with the theoretical results.

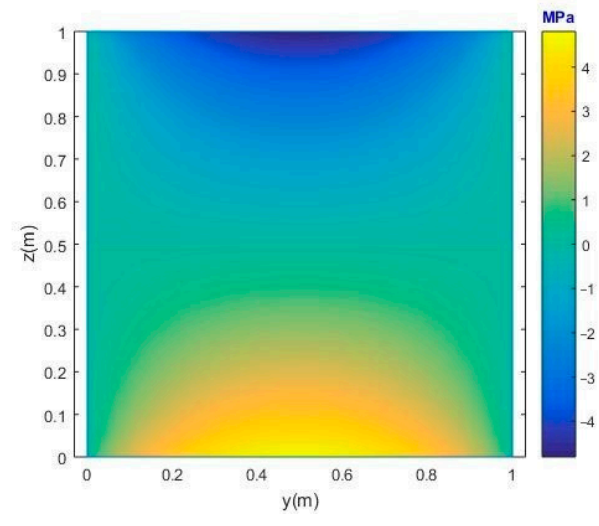

(a)

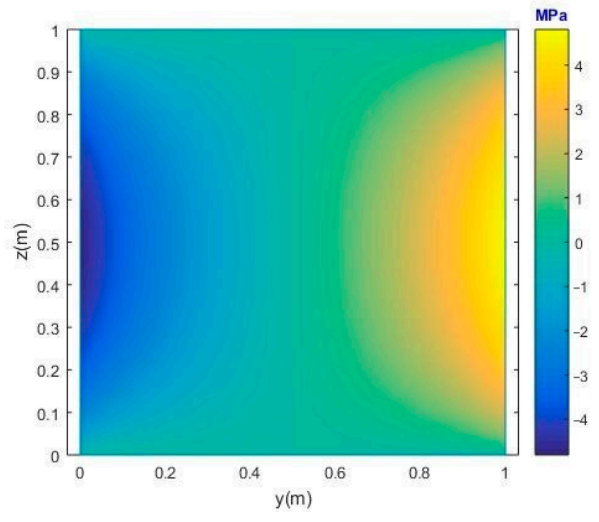

(b)

Figure 4. Computed shear stresses (a) $\tau_{x y}$ and (b) $\tau_{x z}$ for square section of the numerical method (NMB).

It is clear from Table 1 that the results of the maximum shear stress and the polar second moment of area obtained from NMB are in good agreement with the theoretical solution [24].

Table 1. Square section in torsion.

\begin{tabular}{cccc}
\hline Factors & Analytical [24] & NMB & Error, \% \\
\hline$\tau_{\max }[\mathrm{MPa}]$ & 4.80769 & 4.81162 & 0.082 \\
$I_{T}\left[\mathrm{~m}^{4}\right]$ & 0.1406 & 0.14058 & 0.0142 \\
\hline
\end{tabular}


Figure 5 shows the distribution of the shear stress with Poisson's ratios $v=0 ; 0.25$. The stress concentration at $z=0, y= \pm b / 2$ can be seen clearly. We can see the distribution of stress over the width of the section is not constant when the Poisson's ratio $v \neq 0$.

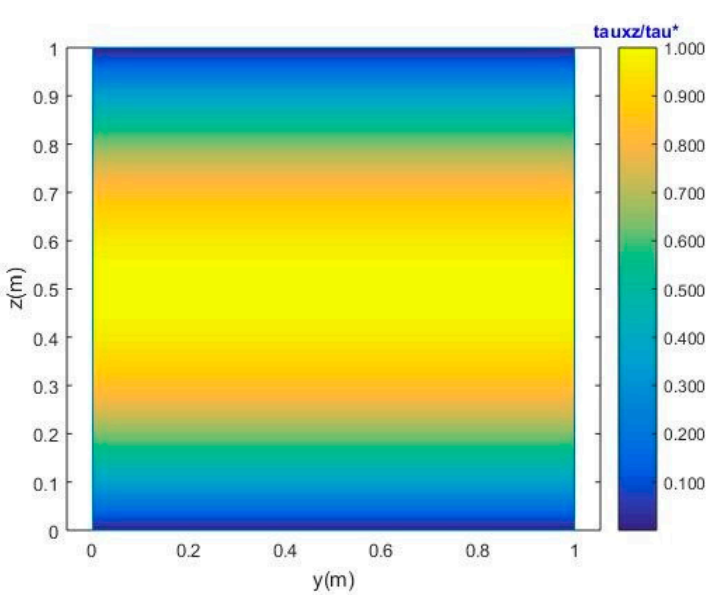

(a)

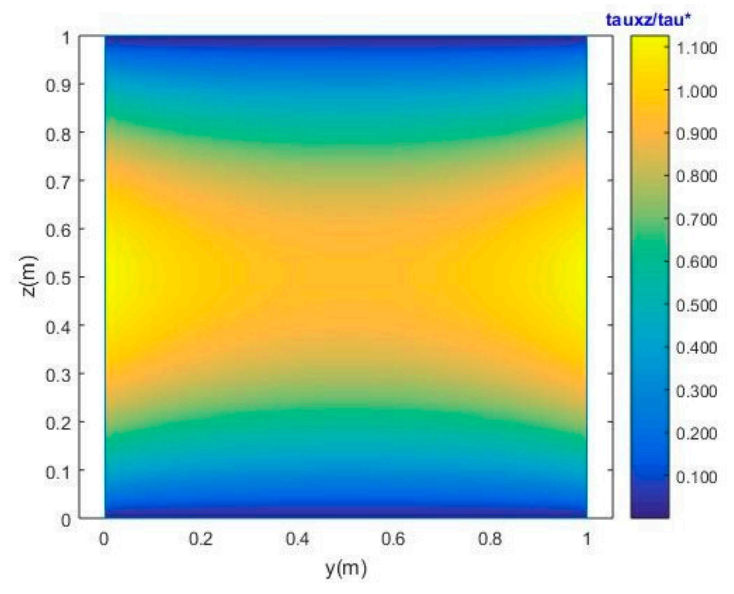

(b)

Figure 5. Normalized shear stress for a square-cross section of NMB with (a) $v=0$ and (b) $v=0.25$.

It can be observed from Tables $2-5$ that the results of shear correction factors $\kappa_{z}$ obtained from rectangular cross-section with different $h / b$ and Poisson's ratio $v$ from NMB are in good agreement with FEAP results [4].

Table 2. Shear correction factors $\kappa_{z}$ with $h / b=2$.

\begin{tabular}{cccc}
\hline Factors & FEAP [4] & NMB & Error, $\%$ \\
\hline$v=0$ & 0.8333 & 0.833335 & 0.0 \\
$v=0.25$ & 0.8331 & 0.833041 & 0.0 \\
$v=0.5$ & 0.8325 & 0.832519 & 0.0 \\
\hline
\end{tabular}

Table 3. Shear correction factors $\kappa_{z}$ with $h / b=1$.

\begin{tabular}{cccc}
\hline Factors & FEAP [4] & NMB & Error, $\%$ \\
\hline$v=0$ & 0.8333 & 0.833335 & $0.0 \%$ \\
$v=0.25$ & 0.8295 & 0.829486 & $0.0 \%$ \\
$v=0.5$ & 0.8228 & 0.822729 & $0.0 \%$ \\
\hline
\end{tabular}

Table 4. Shear correction factors $\kappa_{z}$ with $h / b=0.5$.

\begin{tabular}{cccc}
\hline Factors & FEAP [4] & NMB & Error, \% \\
\hline$v=0$ & 0.8333 & 0.833335 & 0.0 \\
$v=0.25$ & 0.7961 & 0.796066 & 0.0 \\
$v=0.5$ & 0.7375 & 0.737438 & 0.0 \\
\hline
\end{tabular}

Table 5. Shear correction factors $\kappa_{z}$ with $h / b=0.25$.

\begin{tabular}{cccc}
\hline Factors & FEAP [4] & NMB & Error, \% \\
\hline$v=0$ & 0.8333 & 0.833335 & 0.0 \\
$v=0.25$ & 0.6308 & 0.630724 & 0.0 \\
$v=0.5$ & 0.4404 & 0.440378 & 0.0 \\
\hline
\end{tabular}




\subsection{Cross-Section with Varying Width}

The next example is performed with a cross-section with varying width [3,4]. Figure 6 shows the dimension of the cross-section.

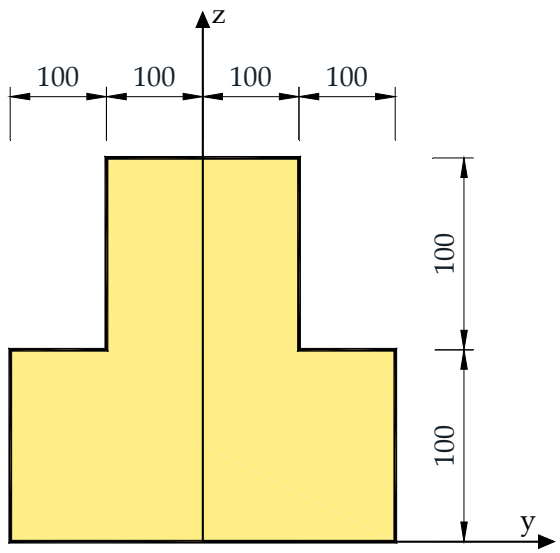

Figure 6. The dimension of cross-section with varying width in $\mathrm{mm}$.

FEAP [3] used 480 elements to get the convergence values, while NMB used only 48 elements (225 nodes). Figure 7 shows the discretization of the cross-section with varying width by NMB.

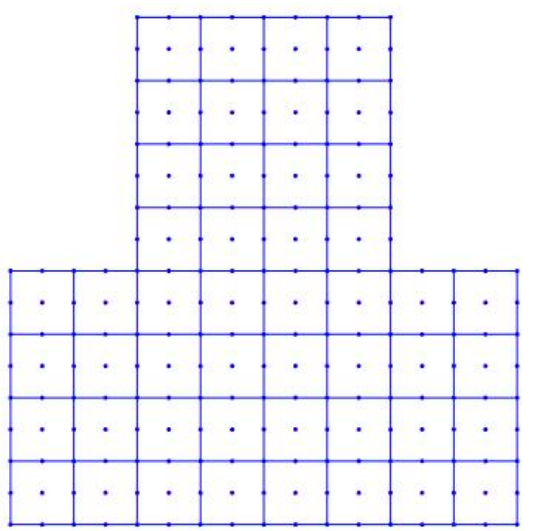

Figure 7. The cross-section divided into 48 elements.

Tables $6-8$ show the errors of the shear correction factors between FEAP and NMB are under $0.33 \%$. Figure 8 shows the distribution of the shear stress $\tau_{x z}$ and the resulting shear stresses with Poisson's ratio $v=0.2$ due to $Q_{z}=-1[\mathrm{kN}]$. The maximum shear stress $\tau_{x z}$ of FEAP and NMB is $2.321 \mathrm{KPa}$ and $2.31 \mathrm{KPa}$, respectively.

Table 6. Shear correction factors $\kappa_{y}, \kappa_{z}$ with $v=0$.

\begin{tabular}{cccc}
\hline Factors & FEAP [4] & NMB & Error, \% \\
\hline$\kappa_{y}$ & 0.7395 & 0.7409 & 0.19 \\
$\kappa_{z}$ & 0.6767 & 0.6788 & 0.31 \\
\hline
\end{tabular}

Table 7. Shear correction factors $\kappa_{y}, \kappa_{z}$ with $v=0.25$.

\begin{tabular}{cccc}
\hline Factors & FEAP [4] & NMB & Error, \% \\
\hline$\kappa_{y}$ & 0.7355 & 0.7372 & 0.23 \\
$\kappa_{z}$ & 0.6753 & 0.6774 & 0.31 \\
\hline
\end{tabular}


Table 8. Shear correction factors $\kappa_{y}, \kappa_{z}$ with $v=0.5$.

\begin{tabular}{cccc}
\hline Factors & FEAP [4] & NMB & Error, \% \\
\hline$\kappa_{y}$ & 0.7294 & 0.7307 & 0.18 \\
$\kappa_{z}$ & 0.6727 & 0.6749 & 0.33 \\
\hline
\end{tabular}

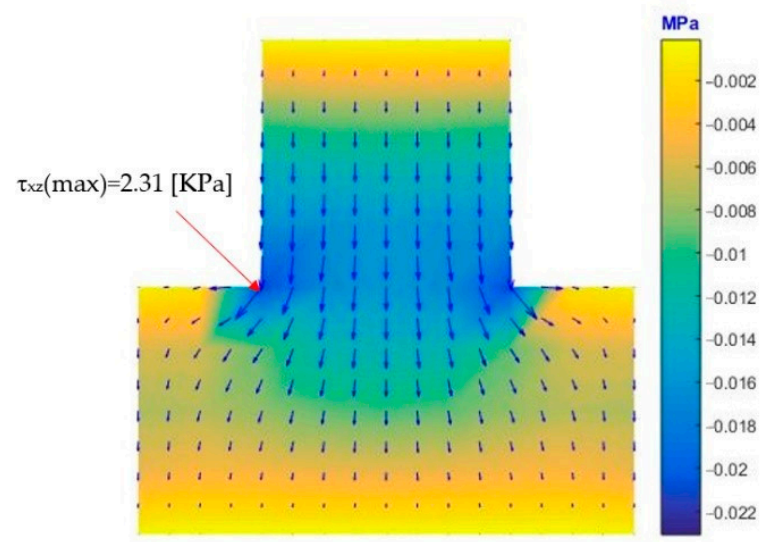

Figure 8. Shear stress $\tau_{x z}$ and resulting shear stresses for $v=0.2$ due to $Q_{z}=-1[\mathrm{kN}]$.

\subsection{Crane Rail A100}

The next example concerns crane rail section A100 according to German standard DIN 536. Figure 9 depicts the dimension of the cross-section. FEAP [3] used 66,934 elements to get convergence values. NMB meshed the crane rail section by 172 elements (773 nodes) to obtain the convergence result. Figure 10a,b illustrate the crane rail section's discretization by FEAP and NMB, respectively.

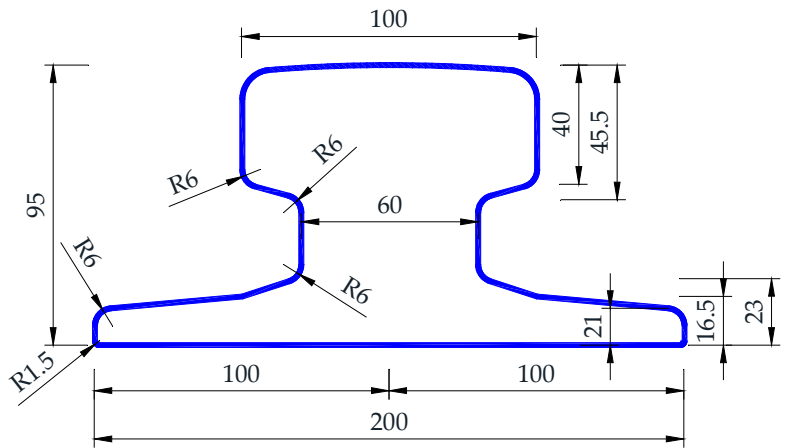

Figure 9. The dimension of cross-section of crane rail A100 in mm.

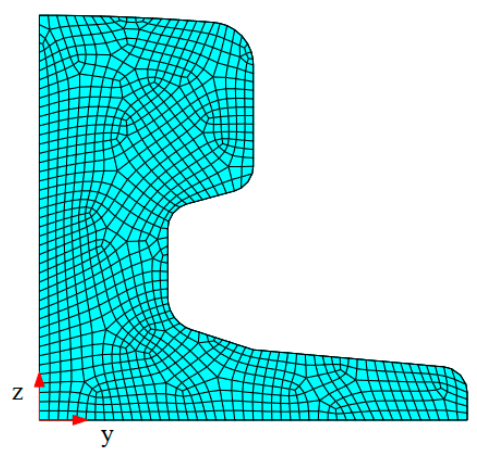

(a)

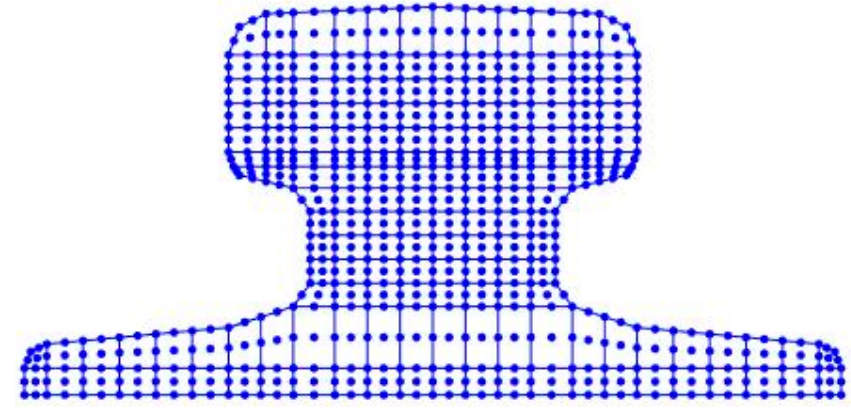

(b)

Figure 10. The discretization of cross-section by (a) FEAP and (b) NMB. 
In Table 9, we present a comparison of the polar second moment of area, the parameter $z_{0}$ between NMB with FEAP. The error is under $0.77 \%$. Figure 11 shows the distribution of the shear stress $\tau_{x z}$ and the resulting shear stresses due to $M_{T}=1$ [kN.m].

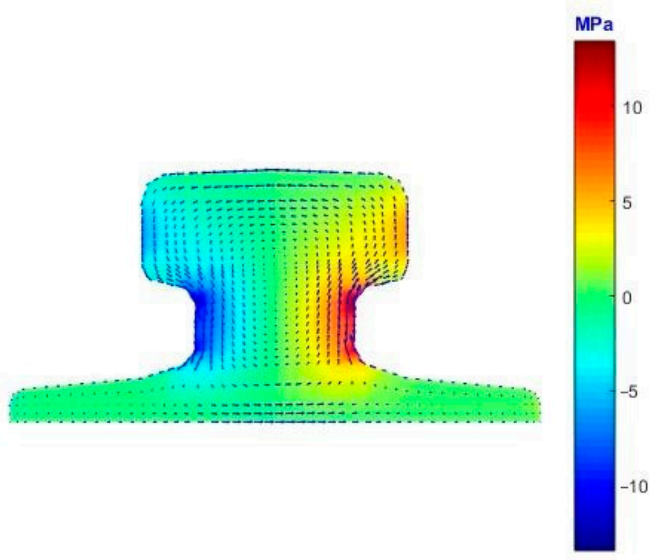

Figure 11. Shear stress $\tau_{x z}$ and resulting shear stresses due to $M_{T}=1[\mathrm{kN} . \mathrm{m}]$.

Table 9. The polar second moment of area and the parameter $z_{0}$

\begin{tabular}{cccc}
\hline Factors & FEAP $[3]$ & NMB & Error, $\%$ \\
\hline$I_{T}\left[\mathrm{~cm}^{4}\right]$ & 670.7 & 675.9 & 0.77 \\
$z_{0}[\mathrm{~cm}]$ & 5.078 & 5.060 & 0.35 \\
\hline
\end{tabular}

Figure 12 shows the distribution of the shear stress $\tau_{x z}$ and the resulting shear stresses with Poisson's ratio $v=0.3$ due to $Q_{z}=-1[\mathrm{kN}]$. The maximum shear stress $\tau_{x z}$ of FEAP and $\mathrm{NMB}$ is $0.41 \mathrm{MPa}$ and $0.42 \mathrm{MPa}$, respectively. Figure 13 depicts the distribution of the shear stress $\tau_{x y}$ and the resulting shear stresses with Poisson's ratio $v=0.3$ due to $Q_{y}=1[\mathrm{kN}]$.

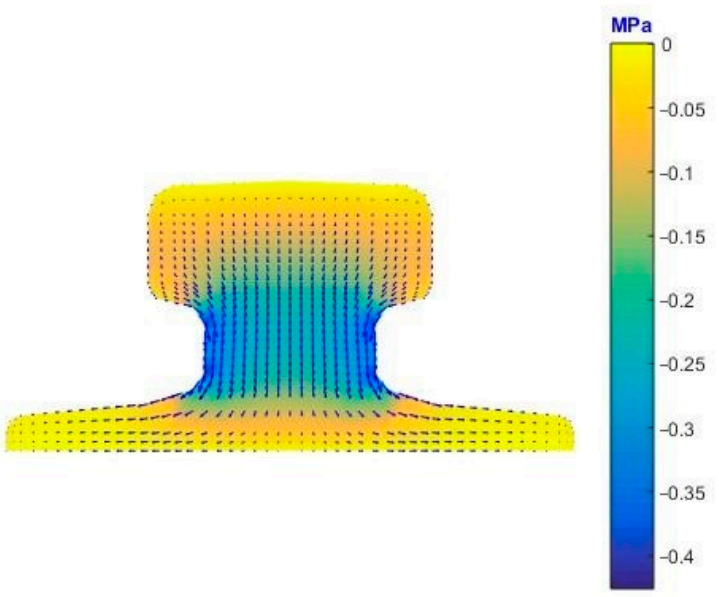

Figure 12. Shear stress $\tau_{x z}$ and resulting shear stresses for $v=0.3$ due to $Q_{z}=-1[\mathrm{kN}]$. 


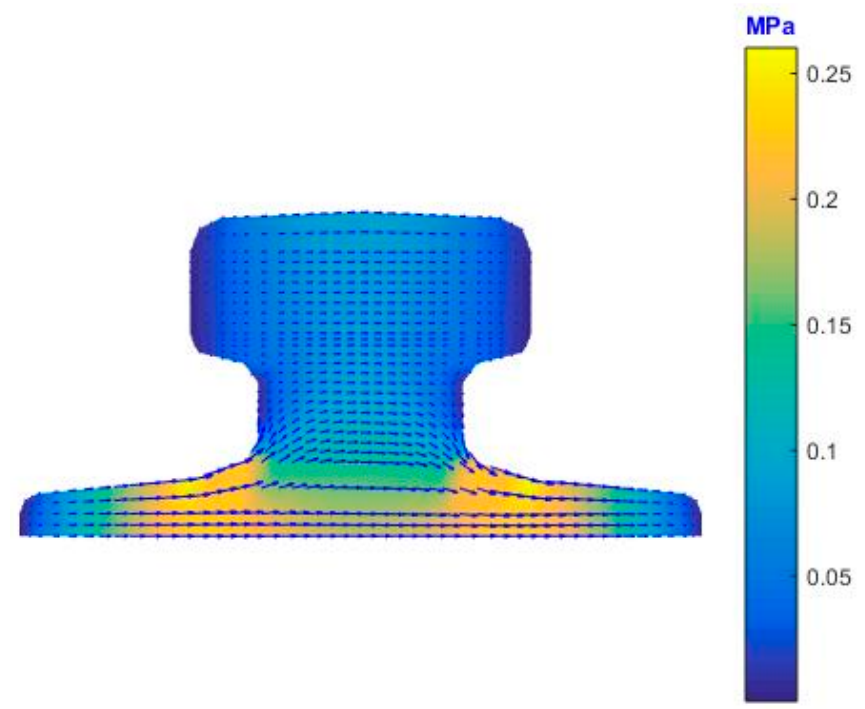

Figure 13. Shear stress $\tau_{x y}$ and resulting shear stresses for $v=0.3$ due to $Q_{y}=1[\mathrm{kN}]$.

Tables 10 and 11 show the errors of the shear correction factors between FEAP and NMB are under $0.71 \%$.

Table 10. Shear correction factors $\kappa_{y}, \kappa_{z}$ with $v=0$.

\begin{tabular}{cccc}
\hline Factors & FEAP [4] & NMB & Error, \% \\
\hline$\kappa_{y}$ & 0.6845 & 0.6867 & 0.32 \\
$\kappa_{z}$ & 0.4474 & 0.4506 & 0.71 \\
\hline
\end{tabular}

Table 11. Shear correction factors $\kappa_{y}, \kappa_{z}$ with $v=0.3$.

\begin{tabular}{cccc}
\hline Factors & FEAP [4] & NMB & Error, \% \\
\hline$\kappa_{y}$ & 0.6836 & 0.6859 & 0.34 \\
$\kappa_{z}$ & 0.4468 & 0.4499 & 0.69 \\
\hline
\end{tabular}

\subsection{Bridge Cross-Section with Doubly Connected Domain}

We consider the bridge cross-sections with doubly connected domain according to Figure 14. We divided the bridge cross-section into 16, 100, 1394, and 3534 elements to check the convergence of NMB and select the value to compare with FEAP. Figure 15 shows the bridge cross-section divided into 100 elements. The comparison of the polar second moment of area and the parameter $z_{0}$ between the two methods was performed to check the torsion problem. The resulting shear stress for the bridge-cross section under torsion $M_{T}=1$ [kN.m] was visualized. In the torsionless bending, the shear correction factors $\kappa_{y}, \kappa_{z}$ and the resulting shear stress were compared between FEAP and NMB. The resulting shear stress for the bridge-cross section under shear forces $Q_{y}=1[\mathrm{kN}]$, $Q_{z}=-1[\mathrm{kN}]$ were also displayed. The value of the polar second moment of area and $z_{0}$ convergence with 3534 divided elements of bridge cross-section can be seen in Table 12. In Table 13, we present a comparison of the polar second moment of area and the parameter $z_{0}$ between NMB with FEAP. The error is under $1.89 \%$. Fifty thousand nodes and uniform mesh were used to achieve the convergence results when using FEAP. The error of the convergence is $0.0047 \%$ [3]. Meanwhile, NMB is convergent with 14,948 nodes. The error of the convergence is $0.0027 \%$, see Table 12 . This result shows that the computation speed of NMB is faster and more efficient than FEAP. 


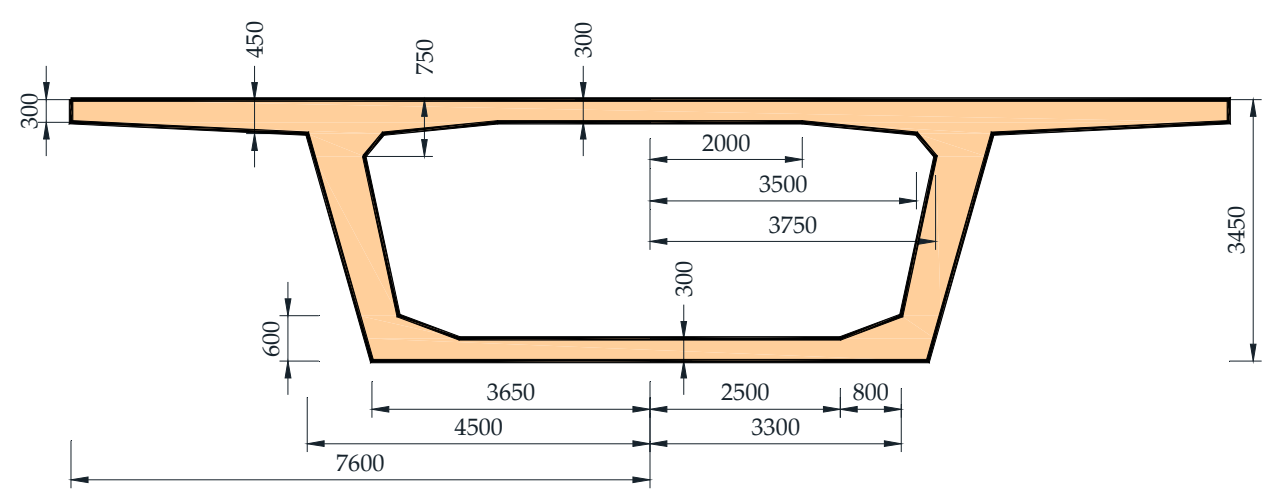

Figure 14. Bridge cross-section with dimensions in $\mathrm{mm}$.

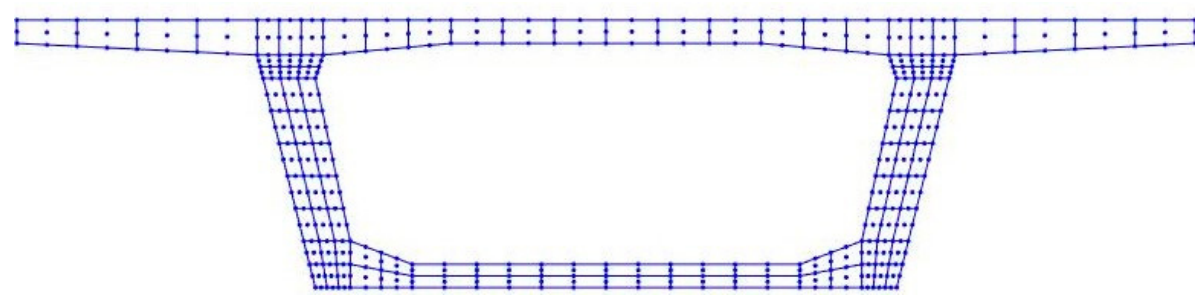

Figure 15. The bridge cross-section divided into 100 elements.

Table 12. The polar second moment of area and $z_{0}$ with number of elements and nodes of NMB.

\begin{tabular}{cccc}
\hline Number of Elements & Number of Nodes & $\boldsymbol{I}_{\boldsymbol{T}}\left[\mathbf{m}^{4}\right]$ & $z_{0}[\mathbf{m}]$ \\
\hline 16 & 96 & 43.583 & 1.771 \\
100 & 506 & 43.3162 & 1.773 \\
1394 & 6028 & 43.2953 & 1.773 \\
3534 & 14,948 & 43.2941 & 1.773 \\
\hline
\end{tabular}

Table 13. The polar second moment of area and $z_{0}$ parameter.

\begin{tabular}{cccc}
\hline Factors & FEAP $[3]$ & NMB & Error, $\%$ \\
\hline$I_{T}\left[\mathrm{~m}^{4}\right]$ & 42.487 & 43.2941 & 1.89 \\
$z_{0}[\mathrm{~m}]$ & 1.775 & 1.773 & 0.112 \\
\hline
\end{tabular}

Figure 16 depicts the distribution of shear stress $\tau_{x y}$ and the resulting shear stresses of the bridge cross-section under torsion $M_{T}=1$ [kN.m] of NMB. The maximum shear stress $\tau_{x y}$ is $7.59 \times 10^{-2}[\mathrm{kPa}]$.

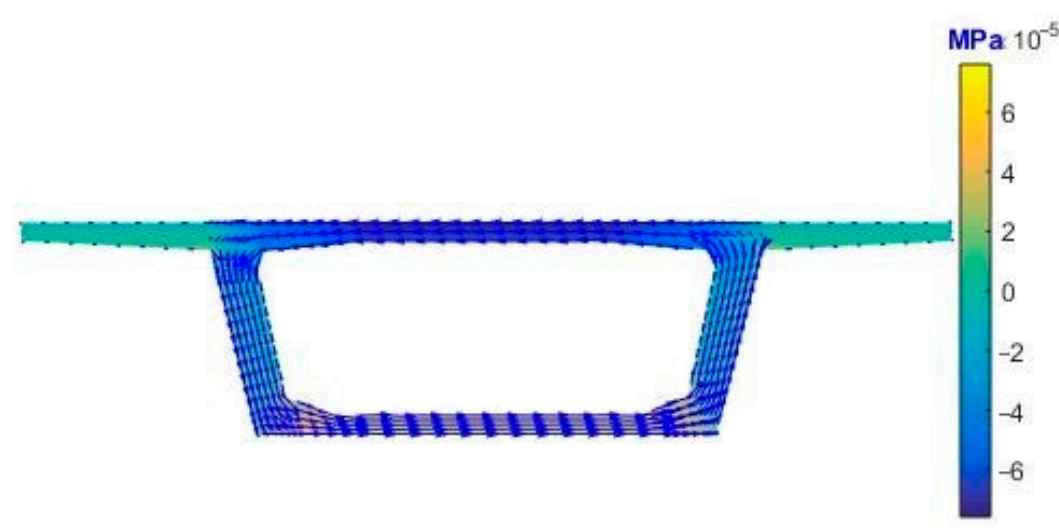

Figure 16. Shear stress $\tau_{x y}$ and resulting shear stresses due to $M_{T}=1[\mathrm{kN} . \mathrm{m}]$ by NMB. 
Figure 17 shows the distribution of shear stress $\tau_{x y}$ and the resulting shear stresses due to $Q_{y}=1[\mathrm{kN}]$. The maximum shear stress $\tau_{x y}$ is $2.05 \times 10^{-1}[\mathrm{kPa}]$. Figure 18 displays the distribution of shear stress $\tau_{x z}$ induced by $Q_{z}=-1[\mathrm{kN}]$. The maximum shear stress $\tau_{x z}$ of NMB and SCAD $[7,8]$ is $4.15 \times 10^{-1}[\mathrm{kPa}]$ and $4.03 \times 10^{-1}[\mathrm{kPa}]$, respectively.

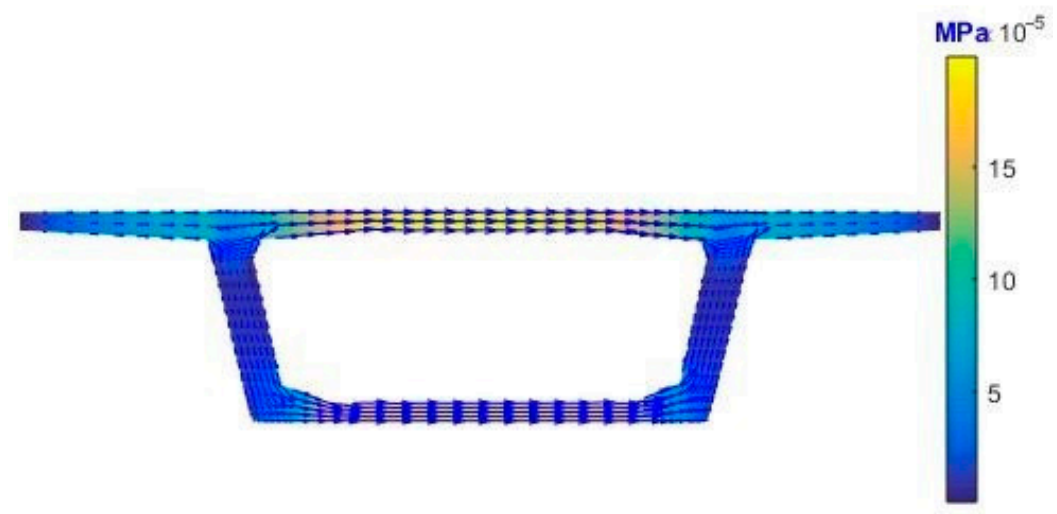

Figure 17. Shear stress $\tau_{x y}$ and resulting shear stresses due to $Q_{y}=1[\mathrm{kN}]$ by NMB.

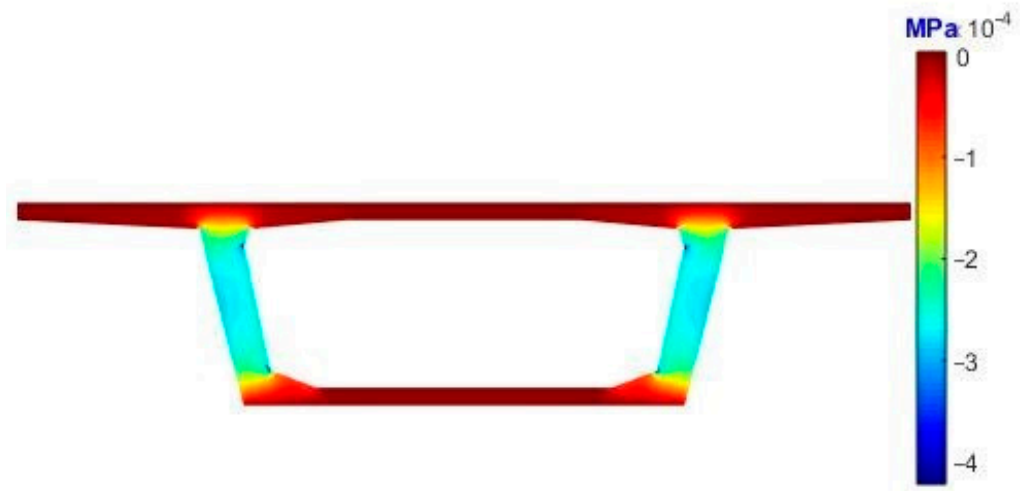

Figure 18. Shear stress $\tau_{x z}$ due to $Q_{z}=-1[\mathrm{kN}]$ by NMB.

Tables 14 and 15 show the errors of the shear correction factors between FEAP and NMB are under $3.04 \%$.

Table 14. Shear correction factors $\kappa_{y}, \kappa_{z}$ with $v=0$.

\begin{tabular}{cccc}
\hline Factors & FEAP [4] & NMB & Error, \% \\
\hline$\kappa_{y}$ & 0.5993 & 0.587293 & 2.00 \\
$\kappa_{z}$ & 0.2311 & 0.238114 & 3.04 \\
\hline
\end{tabular}

Table 15. Shear correction factors $\kappa_{y}, \kappa_{z}$ with $v=0.2$.

\begin{tabular}{cccc}
\hline Factors & FEAP [4] & NMB & Error, \% \\
\hline$\kappa_{y}$ & 0.5993 & 0.587292 & 2.00 \\
$\kappa_{z}$ & 0.2312 & 0.238114 & 2.99 \\
\hline
\end{tabular}

\subsection{Bridge Cross-Section with Multiply Connected Domains}

As a final example, we examined the bridge cross-section with multiply connected domains according to Figure 19 [7]. Poisson's ratio is taken as $v=0.2$. The comparison between NMB and SCAD $[7,8]$ was performed. Figure 20 depicts the bridge cross-section divided into 23 elements. 


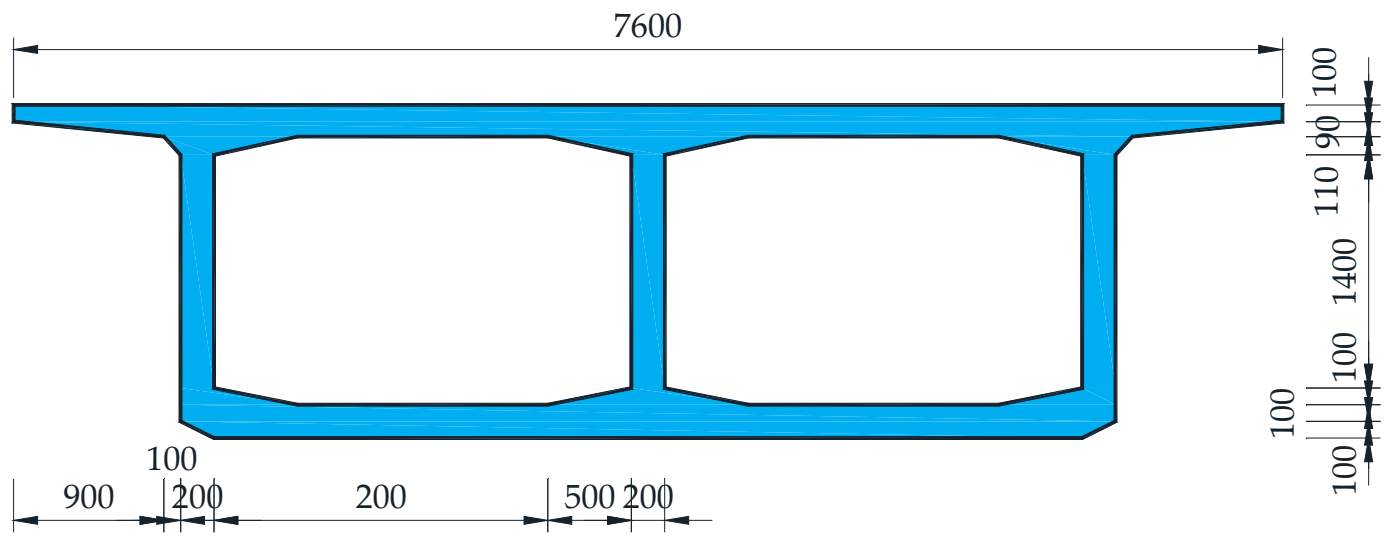

Figure 19. Bridge cross-section with dimensions in $\mathrm{mm}$.

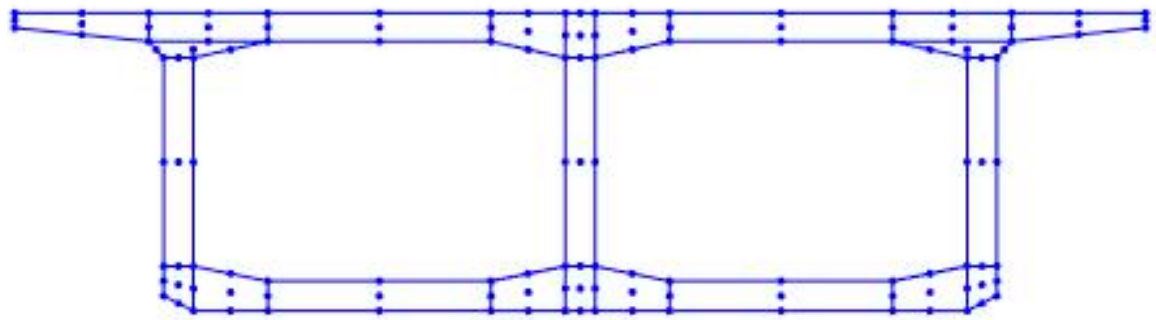

Figure 20. The bridge cross-section divided into 23 elements.

Figure 21 shows the distribution of shear stress $\tau_{x z}$ and the resulting shear stress due to $Q_{z}=-1[\mathrm{kN}]$. The maximum shear stress $\tau_{x z}$ of $\mathrm{NMB}$ and SCAD $[7,8]$ is the same value: $1.08[\mathrm{kPa}]$. Figure 22 depicts the distribution of shear stress $\tau_{x y}$ induced by $Q_{z}=-1[\mathrm{kN}]$. The maximum shear stress $\tau_{x y}$ of NMB and SCAD $[7,8]$ is $1.02[\mathrm{kPa}]$ and $0.96[\mathrm{kPa}]$, respectively.

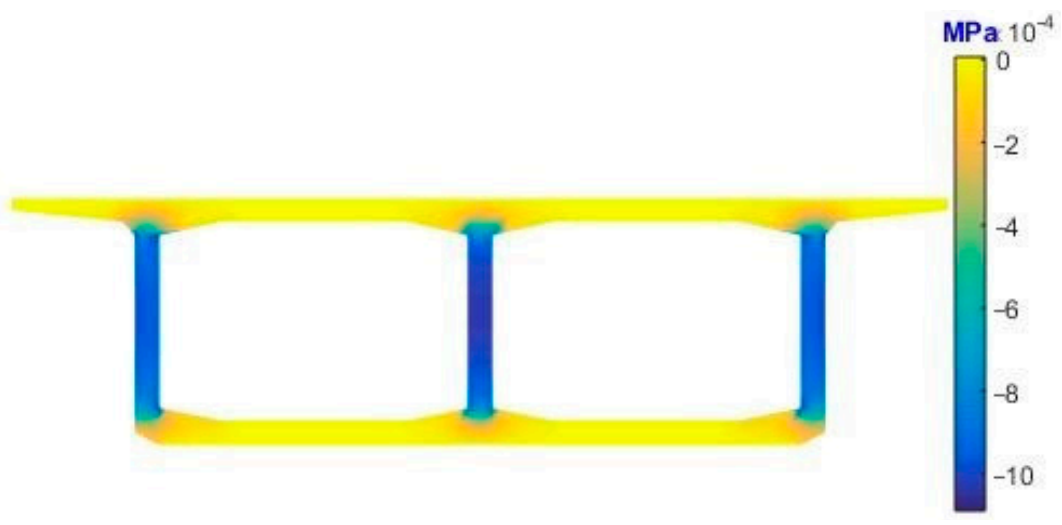

Figure 21. Shear stress $\tau_{x z}$ due to $Q_{z}=-1[\mathrm{kN}]$ by NMB.

Table 16 shows a comparison between SCAD and NMB. It is clear from Table 16 that even when the mesh is not smooth enough (23 elements, 135 nodes), NMB still gives the same results as SCAD using 539 nodes. When using NMB, 2593 nodes (570 elements) are necessary for convergence, while SCAD is 6857 nodes. 


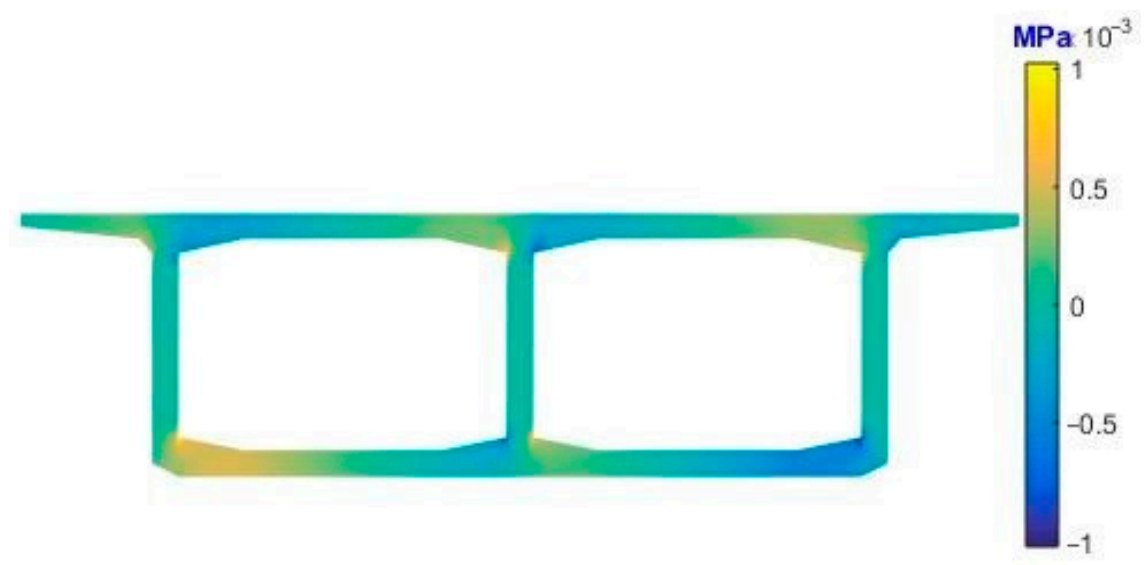

Figure 22. Shear stress $\tau_{x y}$ due to $Q_{z}=-1[\mathrm{kN}]$ by NMB.

Table 16. The shear stress $\tau_{x z}$ due to $Q_{z}=-1[\mathrm{kN}]$, the polar second moment of area, and the shear correction factors $\kappa_{y}, \kappa_{z}$.

\begin{tabular}{cccccc}
\hline \multirow{2}{*}{ Factors } & \multicolumn{3}{c}{ SCAD $[7,8]$} & \multicolumn{2}{c}{ NMB } \\
\cline { 2 - 6 } & 539 Nodes & 1817 Nodes & 6857 Nodes & 135 Nodes & 2593 Nodes \\
\hline $\max \left|\tau_{x z}\right|[\mathrm{kPa}]$ & 1.00 & 1.04 & 1.08 & 0.994 & 1.08 \\
$I_{T}\left[\mathrm{~m}^{4}\right]$ & 5.67 & 5.74 & 5.77 & 5.74 & 5.70 \\
$\kappa_{y}$ & 0.655 & 0.647 & 0.644 & 0.649 & 0.646 \\
$\kappa_{z}$ & 0.276 & 0.268 & 0.266 & 0.274 & 0.268 \\
\hline
\end{tabular}

\section{Conclusions}

From Gruttmann's articles [3,4], we developed the numerical method (NMB) by using nine-noded quadrilateral elements to solve the shear stress for the prismatic beam with arbitrary cross-section. The verification of NMB was carried out by analyzing five examples.

The first example was a simple rectangle cross-section. The comparison results show a good agreement between NMB and FEAP. The second example with varying width crosssection also shows the harmony of NMB and FEAP. However, NMB used a lower number of nodes to achieve the convergence of the problem. The third and fourth examples clearly demonstrate the efficiency of using NMB to achieve convergence results. The fifth example comparing NMB with SCAD commercial software made the advantages of NMB clear.

In this paper, the shear stress problem is solved just for a single material. As a line of further investigation, we intend to extend it to different materials. The study has shown the efficiency and reliability of the method, which allows for more precise analysis and design of cross-sections. Therefore, the development of the method helps engineers to dare to design large span slender structures with reduced dimensions that are also safe. Significant savings of material will have a positive impact on carbon footprint and will enable the sustainable development of humankind.

Author Contributions: Conceptualization, J.N., M.Č., and D.-B.T.; methodology, J.N., M.Č., and D.-B.T.; software, M.Č. and D.-B.T.; validation, J.N. and D.-B.T.; formal analysis, J.N., M.Č., and D.-B.T.; writing_-original draft preparation, D.-B.T.; writing—review and editing, J.N. and M.Č.; visualization, D.-B.T.; supervision, J.N. and M.Č.; project administration, J.N. and M.Č.; funding acquisition, M.C. All authors have read and agreed to the published version of the manuscript.

Funding: This paper was completed thanks to the financial support provided to VSB-Technical University of Ostrava by the Czech Ministry of Education, Youth and Sports from the budget for conceptual development of science, research, and innovations for the 2020 year.

Institutional Review Board Statement: Not applicable.

Informed Consent Statement: Not applicable. 
Data Availability Statement: Data is contained within the article.

Conflicts of Interest: The authors declare no conflict of interest.

\section{References}

1. Collins, M.P.; Bentz, E.C.; Sherwood, E.G.; Xie, L. An adequate theory for the shear strength of reinforced concrete structures. Mag. Concr. Res. 2008, 60, 635-650. [CrossRef]

2. Sung, Y.C.; Chang, D.W.; Cheng, M.Y.; Chang, T.L.; Liu, K.Y. Enhancing the structural longevity of the bridges with insufficient seismic capacity by retrofitting. Struct. Longev. 2009, 1, 1-16.

3. Gruttmann, F.; Sauer, R.; Wagner, W. Shear stresses in prismatic beams with arbitrary cross-sections. Int. J. Numer. Methods Eng. 1999, 45, 865-889. [CrossRef]

4. Gruttmann, F.; Wagner, W. Shear correction factors in Timoshenko's beam theory for arbitrary shaped cross-sections. Comput. Mech. 2001, 27, 199-207. [CrossRef]

5. Taylor, R.L. FEAP-A Finite Element Analysis Program; University of California: Berkeley, CA, USA, 2014.

6. FEAP. 2020. Available online: http:// projects.ce.berkeley.edu/feap/ (accessed on 17 November 2020).

7. Fialko, S.Y.; Lumelskyy, D.E. On numerical realization of the problem of torsion and bending of prismatic bars of arbitrary cross section. J. Math. Sci. 2013, 192, 664-681. [CrossRef]

8. Scadsoft. Available online: https://scadsoft.com/en (accessed on 17 November 2020).

9. Garcia, J.M.B.; Bernat, A.R.M. Coupled model for the non-linear analysis of anisotropic sections subjected to general 3D loading. Part 1: Theoretical formulation. Comput. Struct. 2006, 84, 2254-2263. [CrossRef]

10. Garcia, J.M.B.; Bernat, A.R.M. Coupled model for the nonlinear analysis of sections made of anisotropic materials, subjected to general 3D loading. Part 2: Implementation and validation. Comput. Struct. 2006, 84, 2264-2276. [CrossRef]

11. Poliotti, M.; Jesús-Miguel, B. B-spline sectional model for general 3D effects in reinforced concrete elements. Eng. Struct. 2020, 207, 110200. [CrossRef]

12. Yoon, K.; Lee, P.-S. Modeling the warping displacements for discontinuously varying arbitrary cross-section beams. Comput. Struct. 2014, 131, 56-69. [CrossRef]

13. Navrátil, J.; Michalčík, L.; Kabeláč, J. Praktické Dimenzování Železobetonových a Předpjatých Průřezů Při interakci Vnitřních Sil, Sbornik Př́spěvků 22; Mezinárodní Sympozium Mosty/Bridges 2017: Brno, Czech Republic, 2017; pp. 177-183. ISBN 978-80-86604-71-8.

14. Genoese, A.; Genoese, A.; Bilotta, A.; Garcea, G. A mixed beam model with non-uniform warpings derived from the Saint Venànt rod. Comput. Struct. 2013, 121, 87-98. [CrossRef]

15. Jog, C.S.; Imrankhan, S.M. A finite element method for the Saint-Venant torsion and bending problems for prismatic beams. Comput. Struct. 2014, 135, 62-72. [CrossRef]

16. Urbański, A. Analysis of a beam cross-section under coupled actions including transversal shear. Int. J. Solids Struct. 2015, 71, 291-307. [CrossRef]

17. Beheshti, A. A numerical analysis of Saint-Venant torsion in strain-gradient bars. Eur. J. Mech. A Solids 2018, 70, 181-190. [CrossRef]

18. Sapountzakis, E.J.; Tsiptsis, I.N. Quadratic B-splines in the analog equation method for the nonuniform torsional problem of bars. Acta Mech. 2014, 225, 3511-3534. [CrossRef]

19. Sapountzakis, E.J.; Protonotariou, V.M. A displacement solution for transverse shear loading of beams using the boundary element method. Comput. Struct. 2008, 86, 771-779. [CrossRef]

20. Barone, G.; Iacono, F.L.; Navarra, G. Complex potential by hydrodynamic analogy for the determination of flexure-torsion induced stresses in De Saint Venant beams with boundary singularities. Eng. Anal. Bound. Elem. 2013, 37, 1632-1641. [CrossRef]

21. Paradiso, M.; Vaiana, N.; Sessa, S.; Marmo, F.; Rosati, L. A BEM approach to the evaluation of warping functions in the Saint Venant theory. Eng. Anal. Bound. Elem. 2020, 113, 359-371. [CrossRef]

22. Di Paola, M.; Antonina, P.; Roberta, S. De Saint-Venant flexure-torsion problem handled by Line Element-less Method (LEM). Acta Mech. 2011, 217, 101-118. [CrossRef]

23. Allplan Bridge Features. Available online: https://www.allplan.com/products/allplan-bridge-2019-features/ (accessed on 27 December 2020).

24. Timoshenko, S.; Timoshenko, S.; Goodier, J.N. Theory of Elasticity; Timoshenko, S., Goodier, J.N., Eds.; McGraw-Hill Book Company: New York, NY, USA, 1951.

25. Pilkey, W.D. Analysis and Design of Elastic Beams: Computational Methods; John Wiley \& Sons: Hoboken, NJ, USA, 2002.

26. Zienkiewicz, O.C.; Taylor, R.L.; Zhu, J.Z. The Finite Element Method: Its Basis and Fundamentals; Elsevier: Amsterdam, The Netherlands, 2005.

27. Reddaiah, P. Deriving shape functions for 9-noded rectangular element by using lagrange functions in natural coordinate system and verified. Int. J. Math. Trends Technol. (IJMTT) 2017, 51, 6.

28. SAP2000. Available online: https://www.csiamerica.com/products/sap2000 (accessed on 17 November 2020).

29. Čermák, M.; Sysala, S.; Valdman, J. Efficient and flexible MATLAB implementation of 2D and 3D elastoplastic problems. Appl. Math. Comput. 2019, 355, 595-614. [CrossRef] 